\title{
EXPANSIÓN Y CRISIS DE LA ACTIVIDAD PESQUERA VALENCIANA EN EL SIGLO XIX*
}

\author{
Rafael Viruela Martínez
}

\begin{abstract}
RESUMEN
En el siglo XIX la pesca valenciana tenía muy poca importancia en el conjunto español. A la escasa riqueza piscícola del Mediterráneo hay que añadir el uso de aparejos fruto, más que nada, de una tecnología empírica y tradicional. Las innovaciones se introdujeron con timidez y con cierto retraso con respecto al Atlántico. Probablemente la pesca experimentó un desarrollo en las primeras décadas del siglo, pero de lo que no cabe la menor duda es que desde mediados de la centuria el sector pesquero quedó sumido en una profunda crisis. Las estadísticas disponibles indican una ligera recuperación de la producción a finales del ochocientos. En aquellos momentos la distribución de los desembarcos era muy irregular, con una mayor concentración en el litoral meridional.
\end{abstract}

\begin{abstract}
In the XIX century the Valencian fishing had a very slight importance in the Spanish country. This was due to the scarcity of fishing resources in the Mediterranean and to the use of gears, resulting from an empiric and traditional technology. Innovations were introduced shyly and with a certain delay with respect to the Atlantic. It seems that, the fishing had certain development during the first decades of the century, but what is really sure, is that since mid-nineteenth century the fishing sector succumbed to a deep crisis. The available statistics show a slight recovery of the production at the end of the nineteenth century. At that time, the distribution of the landings was very irregular with a main concentration on the southern littoral.
\end{abstract}

\section{Introducción}

Para el siglo XIX tenemos la suerte de contar con información estadística sobre producción y empleo en el sector pesquero español. El «fraude», que desde siempre se le ha

* Este artículo forma parte de un proyecto de investigación financiado por la Institució Valenciana d'Estudis i Investigació. Departament de Geografia. Universitat de València. 
atribuido a la actividad pesquera, debió ser mayor durante el ochocientos. Los encargados de recoger la información se lamentaban de que los pescadores, «al suministrar los datos que les piden, rebajan siempre la cantidad cogida» (FERNÁNDEZ, 1868, 205-206), ya que «guiados por el interés, hacen ocultación, en cuanto pueden, de aquellas utilidades sobre que pesan los impuestos» (SALAS-GARCÍA, 1876, Apéndice). Los escasos medios humanos y materiales de la Administración impedían subsanar las deficiencias.

La información estadística es, pues, escasa y rudimentaria, con el inconveniente de que los datos se agrupan de forma diferente según los años. Por lo que respecta al País Valencià, al principio se ofrecían para las provincias marítimas de Alacant y València. En los últimos años del siglo se añadieron a aquellos los resultados correspondientes a la provincia de Vinaròs, que hasta ese momento se incluía en la de Tortosa o Tarragona. Según el Derrotero General del Mediterráneo de 1883, Vinaròs tenía jurisdicción desde la Torre de la Sal hasta la Punta de la Banya en el delta del Ebro, incluyendo el puerto de Sant Carles de la Ràpita (MILLÁN, 1984, 13). En consecuencia, los resultados que se ofrecen a continuación deben considerarse como una simple aproximación a la realidad.

\section{Desigual distribución de la actividad pesquera}

Pese a las deficiencias, hemos de felicitarnos al disponer de estadísticas para varios años, sobre todo en la segunda mitad de la centuria. De esta época son los Anuarios y Memorias redactados por los secretarios de la Comisión Permanente de Pesca y la Revista de Pesca Marítima, que constituyen piezas claves para conocer las características del sector pesquero en la segunda mitad del siglo $\mathrm{XIX}^{1}$.

Los valores porcentuales evidencian la desigual distribución de la actividad pesquera española, con un marcado desequilibrio entre el Mediterráneo y el Atlántico. El mayor volumen de pescado se desembarcaba en los puertos gallegos, apreciándose a medida que avanza el siglo un progresivo desplazamiento de la producción a favor de Andalucía, especialmente en el sector atlántico (véase la figura 1). En contrastre con estas dos regiones, que desde entonces han ocupado la primera y la segunda posición en el ranking español, la aportación del litoral mediterráneo era — lo sigue siendo en la actualidadinsignificante.

Las diferencias hay que relacionarlas con la proximidad de las regiones atlánticas a los caladeros propios y externos y, sobre todo, con la mejor dotación en recursos humanos y materiales. Tal como se indica en la figura 2, en 1860 Galicia contaba con un tercio de la flota y de la población pesquera españolas, destacando entre todas las provincias de Vigo y Villagarcía. Las innovaciones técnicas llegaron antes al Atlántico. Según la documentación que hemos consultado, el primer vapor empleado en la pesca se incorporó a la flota de Cádiz en $1865^{2}$ y en 1879 llegó a San Sebastián. A los pocos años alcanzó una rápida

1 En los Anuarios y Memorias de la Comisión, la exposición sigue el orden de materias por el método enciclopédico en el que destacan el bои y/o los artes de arrastre, las almadrabas, las pesquerías extranjeras, la piscicultura, etc., y un detallado comentario de las reales órdenes relacionadas con la pesca. Se dan noticias históricas o literarias y se comentan los adelantos que se estaban dando en el extranjero. Los Anuarios dejaron de publicarse en 1885, cuando la Real Orden de 26 de diciembre de 1884 autorizaba al secretario de la Comisión para que iniciase la publicación de la Revista de Pesca Marítima (GUTIÉRREZ, 1885, 804), que se editó entre 1885 y 1901.

2 En 1865 don Juan González Peredo, del comercio de Cádiz, obtuvo permiso para pescar al arrastre con vapores en aguas marroquíes. Fue tal el éxito alcanzado por los cuatro vapores traídos de Inglaterra que el 7 de diciembre de 1866 se le autorizaba a faenar a 15 millas de la costa española. Sin embargo, no llegó a ejercer esta pesquera, al parecer por la oposición de los pescadores de Cádiz y el Puerto de Santa María (FERNÁNDEZ, 1868, 57-63). 


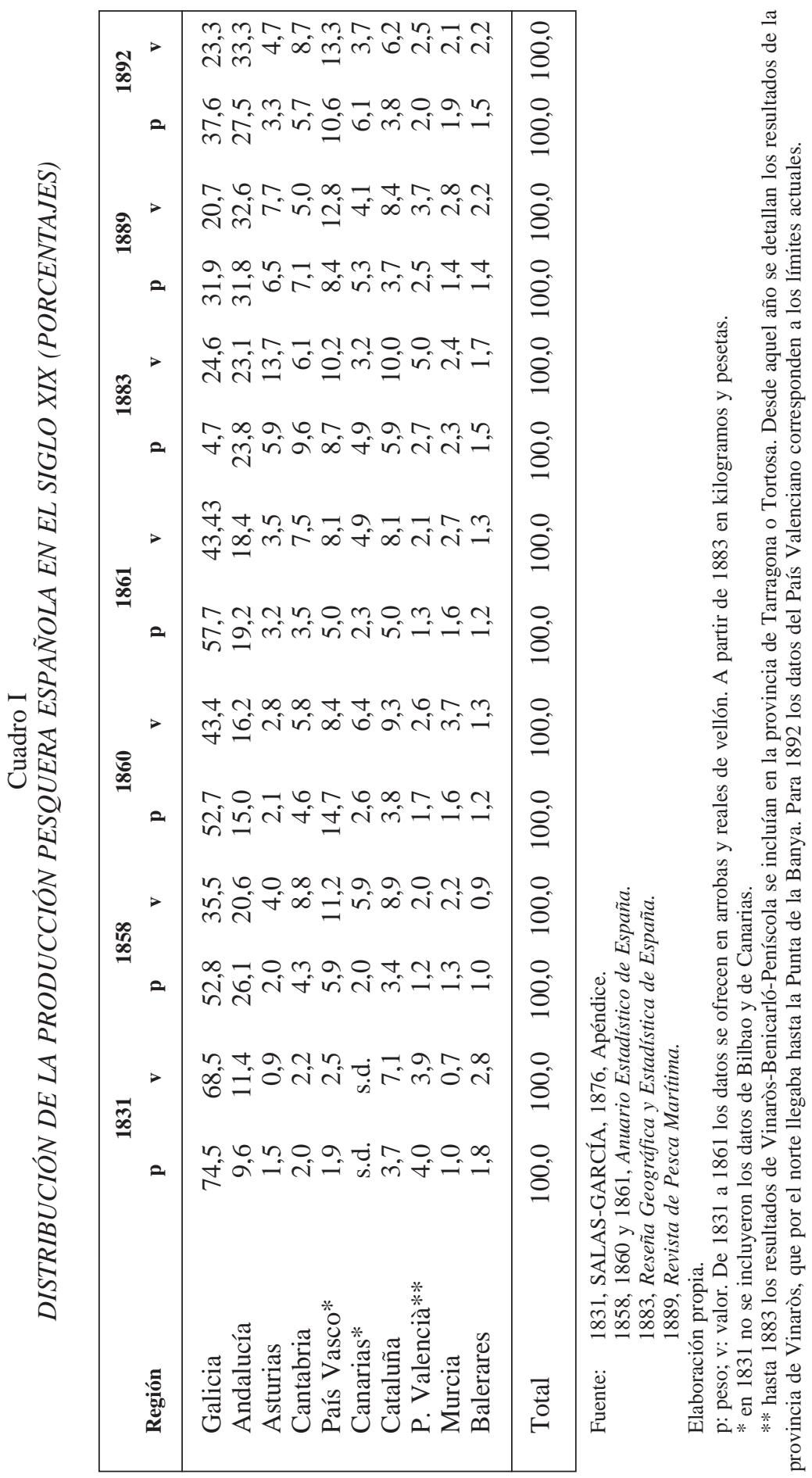




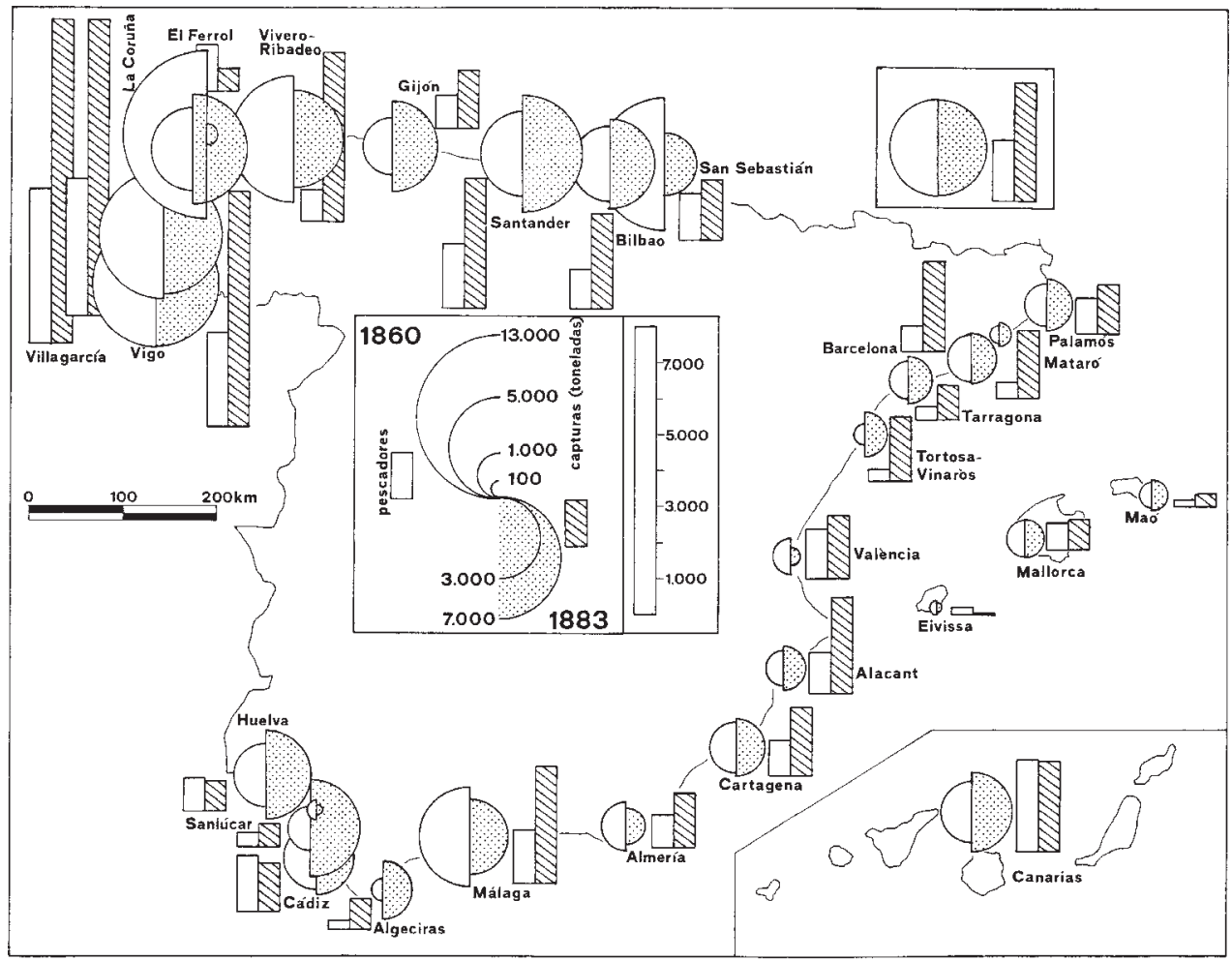

FIGURA 1. Pesca desembarcada y población ocupada en las provincias marítimas españolas, en 1860 y 1883.

difusión en el norte, sobre todo a partir de la Real Orden de 9 de marzo de 1881 que autorizaba el uso de vapores en la pesca (GUTIÉRREZ, 1885, 787).

Las ventajas del vapor se demostraron enseguida. Permitía rastrear los fondos más profundos y vírgenes. La pesca se fue alejando de la costa, alcanzándose en poco tiempo las 10 millas de distancia. Podía faenar en las más ásperas condiciones de tiempo y mar, reduciendo el riesgo de accidentes. Por aquellas mismas fechas, en 1882, llegaba al Cantábrico el rentabilísimo cerco de jareta. La Real Orden de 10 de agosto de 1883 autorizaba su uso en todo el norte de España, llegando a Galicia en 1900 (RODRÍGUEZ, 1923, 230).

La modernización del sector pesquero en el norte peninsular contrastaba con la obsoleta situación en que había quedado el litoral mediterráneo. Ciertamente, en estas costas había técnicas y aparejos muy productivos, como los sardinales y las parejas, pero predominaban los sistemas de pesca tradicionales ${ }^{3}$. Además, las embarcaciones, aunque ligeras porque iban provistas de aparejo latino muy espigado, no podían alejarse mucho ya que no contaban con los brazos suficientes para impulsarlas al remo con calmas de varias horas

3 Según una estadística de 1858 (Junta Central de Estadística, pp. 508-509), el departamento de Cartagena contaba con la práctica totalidad de los palangres (cerca de 10.000), de los trasmallos (más de un millar) y de las nasas (unas 3.500) existentes en España. 


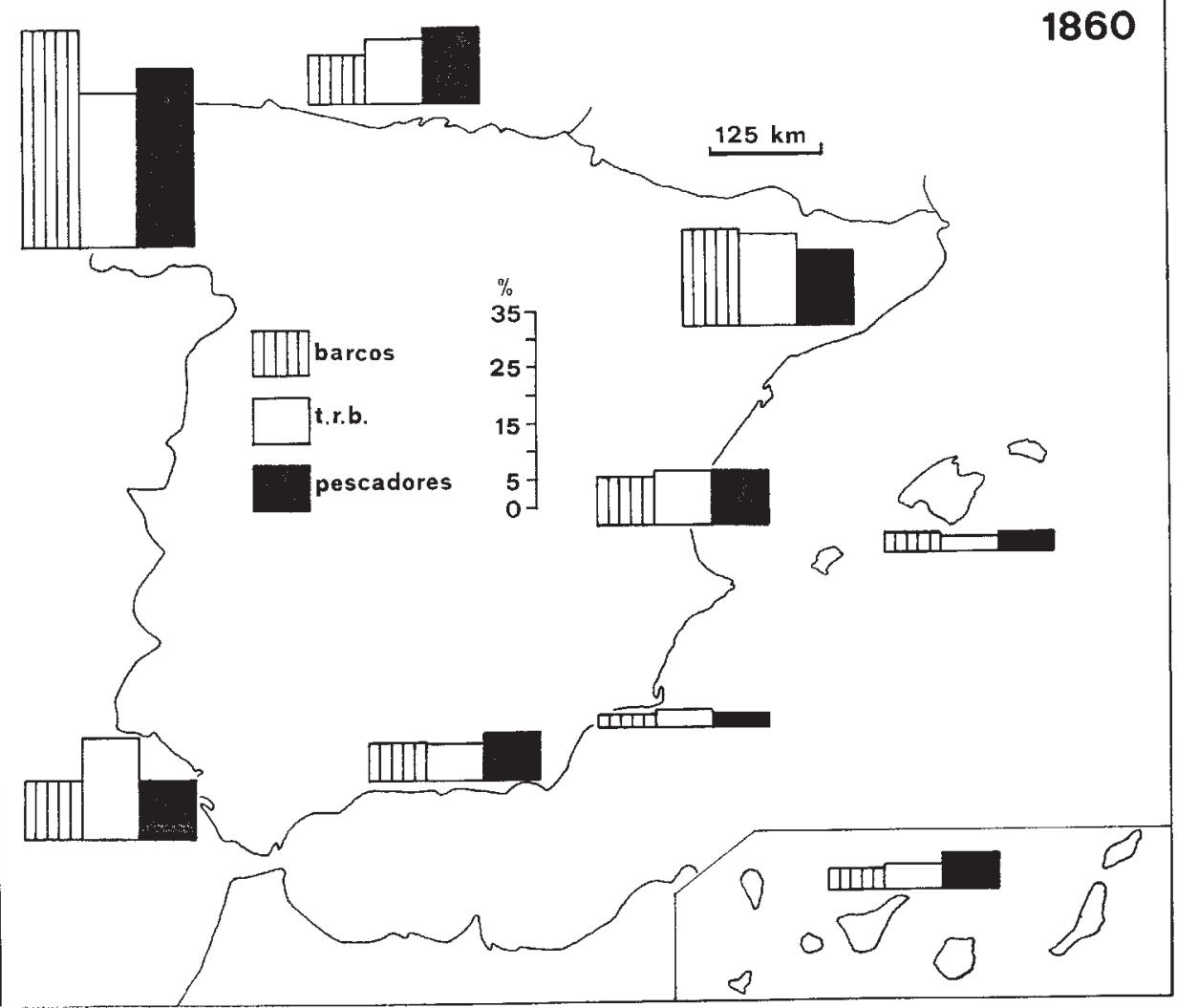

FIGURA 2. Distribución de la flota española, en 1860.

(BORJA, 1892, 258). En consecuencia, la productividad de los pescadores mediterráneos era inferior a la de los que faenaban en el Atlántico. Por término medio, los pescadores del departamento de Cádiz y el Ferrol capturaban el doble que los de Cartagena. En este departamento la productividad de los valencianos era la más baja.

\section{La pesca en el litoral valenciano}

Como se puede apreciar en el cuadro I, el litoral valenciano ocupaba una de las últimas posiciones de la tabla, sólo por delante de Murcia y Baleares. La pesca desembarcada no representaba más que el $2 \%$ del total español ${ }^{4}$. Mayor importancia tenía desde el punto de vista ocupacional, ya que las cerca de 6.000 personas empleadas en 1883 representaban el 9\% de los pescadores españoles. Tal porcentaje evidencia —en relación con la exigua aportación a la producción total española - una estructura económica deficiente, caracterizada por un bajísimo desarrollo de las fuerzas productivas y un proceso de producción íntimamente relacionado con la naturaleza. En aquellos momentos, más de la mitad de la población activa valenciana se ocupaba en el sector primario.

En el litoral valenciano, los pescadores empleaban los anzuelos, las redes de fondo, las almadrabas, las redes barrederas instaladas en embarcaciones movidas a remo o vela y una 
gran cantidad de aparejos fruto más que nada de una tecnología empírica y tradicional. La actividad pesquera se desarrollaba en una estrecha franja litoral que debía estar bajo la mirada vigilante y angustiosa de los familiares del pescador. Como señalaba el secretario de la Comisión Permanente de Pesca, «la esposa y los hijos pasan la vida en continua zozobra esperando el regreso de la frágil barca en que le vieron alejarse de la playa, quizás para no verle jamás» (GUTIÉRREZ, 1885, VI).

En efecto, los siniestros eran frecuentes. Juan Balbás $(1892,702,805,822)$ da testimonio de varios sucesos ocurridos en el litoral norte. El 7 de diciembre de 1883 un temporal causó la muerte a «46 marineros dedicados a la pesca: 40 de Peñíscola, 5 de Benicarló y 1 desconocido». Aquel fue un año particularmente desafortunado para los pescadores valencianos y catalanes (MILLÁN, 1991, 33-34). También en Peníscola, el 28 de septiembre de 1886, naufragaron varias embarcaciones dedicadas a la pesca de bou, «pereciendo veinte marineros de dicha población». A finales de 1891, el 26 de diciembre, hubo que «lamentar varios naufragios de barcos de pesca dedicados á la pesca del bou de Vinaroz y Peñíscola». Al año siguiente, el 20 de octubre, una embarcación zozobraba muy cerca de València, muriendo nueve de sus tripulantes (ANÓNIMO, 1982, 273).

La mayor parte de la producción valenciana se obtenía en el litoral meridional. Las cifras de empleo y producción colocaban a la provincia de Alacant, que abarcaba desde Torrevieja hasta Altea, por delante de València, cuya provincia marítima se extendía de Xàbia a Castelló. En ésta, más de la mitad de las capturas se obtenían en la Albufera. En 1860 la producción del lago fue, según Sabin Berthelot (1867), de 337 toneladas ${ }^{5}$. Cifra inferior a la de años precedentes y que, con el tiempo, no hará sino reducirse todavía más (PARDO, 1942, 183). El cónsul francés atribuía la reducción a la obstrucción del riuet por acumulación de arenas, que impedía la entrada del pescado del mar, y a los continuos aterramientos para ganar tierras de arroz (BERTHELOT, 1868, 390). La Comisión Permanente de Pesca también lamentaba el deplorable estado en que se encontraba la laguna, en donde «la antigua abundancia y bienestar se sustituye por la miseria y la muerte» (FERNÁNDEZ, 1868, 337).

La información estadística recogida en el cuadro anterior revela una aguda crisis de la actividad pesquera en la segunda mitad del siglo XIX. Pero, en opinión que compartimos con Compán Vázquez (1975-76, 94), en la primera mitad de la centuria la pesca experimentó un extraordinario desarrollo. A mediados de siglo, según se deduce de las descripciones de Madoz (1845), se trataba de una actividad practicada en multitud de núcleos costeros valencianos.

\subsection{Expansión de la pesca en la primera mitad del siglo}

El caso de los poblados marítimos de València es un claro ejemplo del desarrollo del sector en los primeros años del XIX. A finales del setecientos (en 1786) el brigadier de la Armada, don Luis Muñoz de Guzmán, certificaba que la flota del Grau, Cabanyal y Canyamelar estaba integrada por 263 embarcaciones de palangre y 32 de bou $^{6}$. En 1821 ya había 466 barcos que pescaban con palangres y otros artes y 62 dedicados a la modalidad

4 En 1831 el porcentaje debió ser inferior al recogido en el cuadro ya que no se pudo contar con la información correspondiente a las provincias de Canarias y Bilbao.

5 La noticia proporcionada por Berthelot la hemos tomado de Compán Vázquez (1975-76, 94).

6 En realidad, a finales del siglo XVIII había 66 embarcaciones de bou afectas al Grau, Cabanyal y Canyamelar, pero sólo 32 faenaban en nuestras aguas. El resto actuaba en las costas andaluzas. 

EL SIGLO XIX

a) Producción (en toneladas)

\begin{tabular}{|crrrrr|}
\hline Año & Alacant & València & Vinaròs & País Valencià & España \\
\hline 1831 & $1.411,5$ & $1.003,9$ & & $2.415,4$ & $60.305,2$ \\
1858 & 498,5 & 574,4 & & $1.072,9$ & $92.393,6$ \\
1860 & $690,-$ & 588,1 & & $1.278,1$ & $73.173,4$ \\
1861 & 541,4 & 518,1 & & $1.059,5$ & $82.348,8$ \\
1883 & 991,9 & $133,-$ & $693,-$ & $1.817,9$ & $67.604,-$ \\
1889 & $1.095,6$ & 403,8 & 452,6 & $1.952,-$ & $78.604,8$ \\
1892 & $1.124,2$ & 444,2 & 84,3 & $1.652,7$ & $82.814,-$ \\
\hline
\end{tabular}

b) Flota y población pesquera

\begin{tabular}{|rrrrrr|}
\hline \multicolumn{1}{|c}{ Año } & Alacant & València & Vinaròs & País Valencià & España \\
\hline $1831 \mathrm{E}$ & 914 & 786 & & 1.700 & 9.214 \\
$\mathrm{H}$ & 3.057 & 3.114 & & 6.171 & 52.315 \\
$1858 \mathrm{E}$ & 173 & 272 & & 445 & 8.223 \\
$\mathrm{H}$ & 1.215 & 1.321 & & 2.981 & 33.236 \\
$1860 \mathrm{E}$ & 251 & 266 & & 517 & 8.607 \\
$\mathrm{H}$ & 1.172 & 1.385 & & 2.557 & 34.257 \\
$1861 \mathrm{E}$ & 212 & 269 & & 481 & 8.192 \\
$\mathrm{H}$ & 1.131 & 1.449 & & 2.580 & 32.927 \\
$1883 \mathrm{E}$ & 496 & 519 & 461 & 1.476 & 15.735 \\
$\mathrm{H}$ & 2.692 & 1.770 & 1.486 & 5.938 & 66.210 \\
$1889 \mathrm{E}$ & 319 & 357 & 194 & 870 & 19.725 \\
$\mathrm{H}$ & 1.534 & 1.433 & 860 & 3.827 & 63.910 \\
$1892 \mathrm{E}$ & 535 & 411 & $?$ & 946 & 14.726 \\
$\mathrm{H}$ & 2.118 & 1.365 & $?$ & 3.483 & 67.197 \\
\hline
\end{tabular}

Fuente: la misma del cuadro anterior. Elaboración propia.

E: embarcaciones. H: hombres empleados.

de arrastre que, tal como se indica en el cuadro III, eran auxiliados por 25 «enviadas» para transportar el pescado hasta la playa.

En el mismo período, la población ocupada se cuadruplicó. Si a finales del XVIII había 576 hombres, en 1820 el número de matriculados ascendía a 2.307 (Observaciones, 1821, 16). De estos, 735 (un tercio del total) se ocupaban en la pesca del bou, que proporcionaba más de la mitad de las capturas que pasaban por la Pescadería de València (VIRUELA, 1993 , 149). Esta modalidad de pesca era el sustento de «500 familias muy numerosas, por la admirable fecundidad de las mugeres de aquel distrito» (Observaciones, 1921, 3). 


\begin{tabular}{|c|c|c|c|c|}
\hline \multirow[t]{2}{*}{ Tamaño } & Embarcaciones & \multicolumn{2}{|c|}{ Tripulación } & \multirow[b]{2}{*}{ Otros* } \\
\hline & & Hombres de mar & Muchachos & \\
\hline De 16 a $12 \mathrm{tn}$ & 12 & 72 & 12 & \\
\hline de 15 a 25 tn & 50 & 500 & 50 & \\
\hline de 4 a 6 th («enviadas») & 25 & & & \\
\hline Total & 87 & 572 & 62 & 101 \\
\hline
\end{tabular}

Fuente: Observaciones sobre la pesca llamada de bou, p.23.

Elaboración propia.

* Armadores, aprendices para composición y tinte de artes y empleados de las yuntas de bueyes para varar las embarcaciones.

La aparición de un gran número de pequeños y medianos núcleos de población a lo largo del litoral parece corroborar la hipótesis de la expansión de la actividad pesquera. Es muy probable que aquel desarrollo urbano estuviese liderado por pescadores. En la mayoría de los casos emigraron hacia las playas próximas a las ciudades y ricas en pesca. Es lo que ocurrió, por ejemplo, en el Grau de València (VICENT CORTINA, 1954), a donde se dirigirían los pescadores que hasta esos momentos residían en el barrio de Russafa ${ }^{7}$.

El nacimiento, a principios de la centuria, del Poble Nou de la Vila Joiosa se ha relacionado con la intensificación de la actividad pesquera (ROSSELLÓ, 1984, 204; OLIVER, 1987, 96). En el puerto de Dénia el aumento de la población marinera, de características distintas a los habitantes de la ciudad (Dalt Dénia), se tradujo en la segregación en 1837 del Pueblo Nuevo de Diana (Baix la Mar). Dos años después, una Real Orden de 2 de mayo de 1839 acabó con la autonomía de la nueva población.

En algunas playas, lo que hasta ese momento eran barracas o chozas, en las que se almacenaban las redes y aparejos o servían de morada temporal a los pescadores domiciliados en núcleos apartados de la costa, se convirtieron en lugares permanentes de habitación, experimentando un rápido crecimiento. Así debió ocurrir en el Grau de Castelló que, según Pascual Madoz (1845, I, 228), se estaba poblando de forma sorprendente desde hacía pocos años $^{8}$. Hasta entonces, los pescadores castellonenses habían preferido vivir en el carrer dels Peiscadors, en el barrio de Santo Tomás de la capital de la Plana (BURRIEL, 1971, 216,217 y 282 ).

7 A principios del siglo XIX, la mayor parte de los pescadores valencianos seguían viviendo en Russafa. Así se deduce de un documento conservado en el Archivo Municipal de València: Libro de la Comunidad de Pescadores del Real Patrimonio. En este libro se levantó acta de una reunión que tuvo lugar en octubre de 1802 en casa del Jurado de la Comunidad y a la que fueron convocados «todos los pescadores de la citada comunidad habitantes de Valencia, Ruzafa y demas donde tienen sus distritos y dormitorios».

8 El testimonio de Pascual Madoz se ha podido corroborar con la documentación conservada en el archivo municipal de Castelló. Durante el siglo XVIII y primeros años del XIX, los pescadores solicitaban permiso para cortar algunos pinos del «Pinar» con el fin de construir una barraca. El 24 de mayo de 1786, Pasqual Arnau lo solicitaba «para hacer una barraca en la playa del mar... para custodiar los arreos de la barca». En cambio, en el siglo XIX las solicitudes se pedían para levantar casas. El 22 de mayo de 1839, José Arnau exponía «que la barraca que posehe en la Playa de la Mar desea reducirla á casa». Otros solicitaban permiso para ampliar las barracas que poseían. Véase la serie de Memoriales, años 1770 a 1849 (legajos, 3 a 8), en el Archivo Municipal de Castelló. 
A mediados de siglo las capturas se redujeron a la mitad en consonancia con la drástica disminución de los medios de producción (véase el cuadro II). La crisis pesquera afectó a toda España y fue muy lamentada en la bibliografía especializada de la época (COMPÁN, 1975-76, 94). La constitución en 1865 de la Comisión Permanente de Pesca para «mayor y más perfecto desarrollo de la industria pesquera» lo corrobora.

No resulta fácil considerar en toda su amplitud las razones del cambio ya que no disponemos de la documentación necesaria. En el litoral valenciano dos de sus principales pesquerías, la de almadraba y la del bou, mostraban claros síntomas de decadencia.

\subsubsection{El declive de las almadrabas}

En 1867 las almadrabas caladas en el litoral valenciano proporcionaron más de 500 toneladas de pescado, cantidad que representaba aproximadamente la mitad de las capturas del momento. Hemos de dar la razón a Viravens $(1876,334)$ cuando afirmaba que la pesca de atunes con almadraba «es la más abundante que se conoce en las costas Alicantinas». Sin embargo, en opinión de la Comisión Permanente de Pesca, la más antigua pesquera era una sombra de lo que fue (FERNÁNDEZ, 1868, 135). A tenor de las investigaciones realizadas por el Ministerio de Marina, el ocaso empezó hacia 1824 (GARCÍA SOLÁ, 1880,38 debido, entre otras razones, a los complicados trámites que debían formalizar los pescadores para el calamento de las almadrabas, al elevado precio de la sal y a los arrastres de las parejas de bou en las proximidades de la costa.

La Comisión Permanente puso especial interés en el fomento de esta pesquera porque no era perjudicial para la reproducción de las especies. Entre sus propuestas, recogidas en el Reglamento para el régimen y disfrute de las almadrabas de 1866 (FERNÁNDEZ, 1868, 139-144), destacaba la posibilidad de crear nuevos establecimientos (artículo 25 del reglamento) y la prohibición de utilizar otras redes a menos de dos millas a barlovento de la almadraba (artículo 23). El proyecto interesaba al gobierno por cuanto significaba una importante fuente de ingresos. En efecto, las almadrabas eran propiedad del Estado (artículo 1), que concedía su usufructo en pública subasta para períodos de cuatro años prorrogables de dos en dos hasta un máximo de dieciséis años (artículo 9) ${ }^{9}$. En la licitación, la cantidad de partida se fijaba en función de los rendimientos de años anteriores (artículo 11).

Pese a los desvelos de la Comisión, la crisis almadrabera era ostensible. En el litoral valenciano, la ausencia de licitadores en muchas subastas y los bajos precios con que se adjudicaron varias concesiones, eran claros síntomas del declive. Con el tiempo dejaron de calarse un gran número de almadrabas.

En la figura 3, se ha representado la producción y la población ocupada en las almadrabas que estuvieron en activo en 1867 y en $1899^{10}$. Los mayores rendimientos se obtenían en

9 El Reglamento de 1899 (Ministerio de Marina) establecía que el período de disfrute debía ser de dieciséis años, aunque se podía rescindir el contrato al final de cada cuatro años.

10 Además de las que se indican en el mapa, a lo largo del siglo XIX se calaron alamadrabas en: Cova dels Llops, la Granadella, Cala Conill, Torre de la Talaia y Racó d'Albir. No se autorizó el calamento de nuevas almadrabas en Torre de l'Aigua, Cala Perchel, el Calamaret y Cap Negret. Tampoco se permitió el establecimiento de una almadraba para sardinas (almadrabilla) en Benidorm. A todas ellas había que añadir la que en 1871 se ensayó en Benicàssim. En diciembre de 1899 estaban pendientes de salir a subasta las de Coveta Fumada y Riu Torres. Véanse a este respecto las Memorias y Anuarios de la Comisión Permanente de Pesca y la Revista de Pesca Marítima. 


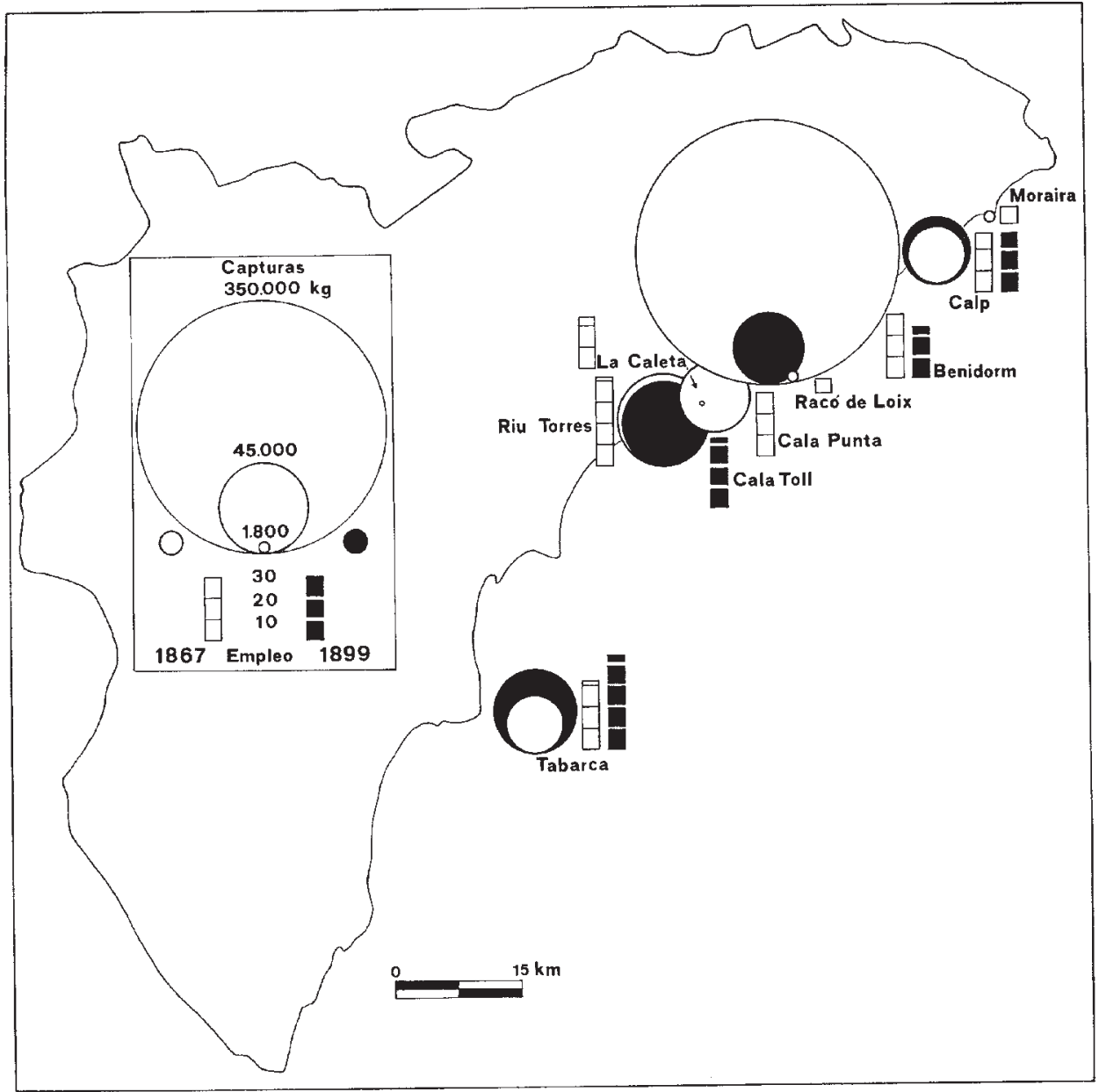

FIGURA 3. Pesca desembarcada y población ocupada en las almadrabas valencianas, en 1867 y 1899.

las de Benidorm, Tabarca y la Vila Joiosa (Cala Punta, la Caleta, Riu Torres...) que, junto a la de Calp, eran las que se mantenían en activo al finalizar el siglo. Todas las almadrabas, incluso las más productivas, conocieron una reducción en el precio de salida en la subasta. Disminución que obedecía a las pérdidas declaradas por los arrendatarios en temporadas anteriores. Muchos tendrían interés en ocultar la realidad («persisten en desfigurar los datos estadísticos»), declarando pérdidas en temporadas anteriores para que los precios de licitación en las siguiente subasta fuese bajo (GARCÍA SOLÁ, 1876, 4).

\subsubsection{Limitaciones a la pesca de arrastre por parejas}

Durante el siglo XIX y como ocurriera en la centuria anterior (VIRUELA, 1993, pp. 151-155), los métodos de arrastre se vieron envueltos en una viva polémica mantenida entre sus detractores y defensores. Quienes practicaban esta modalidad de pesca destaca- 
ban su carácter inofensivo y la mayor productividad del $b o u^{11}$. Otros, en cambio, consideraban esta modalidad de pesca como la más perjudicial (BERTHELOT, 1868, capítulo VII $)^{12}$. Don Felicísimo Llorente y Olivares, en Estudios piscícolas. Examen de la pesca denominada parejas de Bou, y su aplicación en el golfo de Valencia, hizo una detallada descripción del fondo marino, acompañado de un croquis confeccionado por un patrón de pesca, llegando a la conclusión de que los arrastres estaban arruinando el «cañamizar», uno de los comederos más ricos del litoral valenciano (FERNÁNDEZ, 1868, 81).

Entre mediados del siglo XVIII y mediados del XIX llegaron al Ministerio de Marina dieciocho expedientes a favor y treinta y cuatro en contra. Este volumen de documentos dio motivo a la promulgación de treinta y tres decretos, reales cédulas, ordenanzas y reglamentos que afectaban a la pesca de arrastre por parejas (BERTHELOT, 1868, 299302). En ocasiones la Administración optaba por prohibir el bou, en otras proclamaba la libertad de pesca o fijaba vedas, revisándolas constantemente ${ }^{13}$. A veces porque surgían graves problemas de abastecimiento en los mercados $\mathrm{y}$, muy especialmente, cuando razones de orden público aconsejaban satisfacer las demandas populares. Los pescadores alegaban miseria y falta de trabajo a causa de las prohibiciones y el gobierno acababa cediendo. Los resultados de este caos legislativo fueron ruinosos y provocaron una aguda crisis, lamentada por todos los pescadores (Asociación de Patronos Pescadores de Barcelona, 1898, 59).

Así las cosas, en la segunda mitad del XIX, las autoridades estaban dispuestas a adoptar una política más restrictiva. A propuesta de la recién constituida Comisión Permanente de Pesca, en 1865 se aprobó un reglamento al que las asociaciones de pescadores calificaron de «norma prohibitiva hasta la exageración». Su articulado trataba de regular el período y los límites para pescar. No se podía faenar a menos de 12 millas de la costa y debía cesar toda actividad en los meses de junio, julio, agosto y septiembre u octubre, según las regiones ${ }^{14}$. El principal objetivo era la progresiva reducción de la flota hasta su total desaparición, ya que no se permitía la construcción de nuevas embarcaciones, ni siquiera en sustitución de las que quedasen inutilizadas.

Sin embargo, la flota arrastrera española apenas se redujo. En 1865 estaba integrada por 729 embarcaciones y en 1878 todavía contaba con 715 unidades. La Administración no dotó a los departamentos marítimos de los medios necesarios para vigilar el estricto cumplimiento de las normas ${ }^{15}$. Respetar o infringir la ley dependía de la libre elección de

11 Los partidarios del bou aseguraban que «labra el fondo de los mares, como el arado la tierra, para mejorar su producción, destruyendo plantas nocivas que ahuyentan las especies marítimas útiles para el público consumo» y añadían «es causa del abaratamiento de los precios del pescado en los mercados, poniéndolo al alcance de las clases sociales humildes» (Asociación de Patronos Pescadores de Barcelona, 1898, 58).

12 Se criticaba a la pesca de arrastre por parejas «porque remueve los fondos... destruyendo la flora marina, llegará una época en la cual ni por el tamaño ni por la abundancia de aquellos [peces] se recompensen los afanes de los pescadores, produciéndose una pérdida no sólo para un tiempo determinado, sino para las generaciones sucesivas» (VERA, 1887 a, 134).

13 A este respecto, la opinión de los propios pescadores resume la contradictoria reglamentación de la actividad: «el legislador español, al reglamentar esta clase de pesca, dió visibles muestras de constante vacilación, pues mientras unas veces trató de aniquilarla con disposiciones de marcado carácter prohibitivo, tendióle otras compasivamente la mano...» (Asociación de Patronos Pescadores de Barcelona, 1898, 57).

14 La flota comprendida entre Sanlúcar y Cádiz comenzaba la campaña el 1 de septiembre, el 15 de ese mes lo hacía la que faenaba entre el Estrecho y el Delta del Ebro (la valenciana, pues) y en octubre empezaban a pescar las embarcaciones de las provincias de Tarragona y Barcelona.

15 En ocasiones, ni siquiera se sancionaba a los que contravenían las normas. Así se expresaba el comandante del vapor «Vigilante», teniente de navío don Francisco de Paula, encargado de la vigilancia del golfo de València: «Por dos veces he cogido dos parejas incumpliendo el Reglamento, y dada cuenta á la autoridad del Departamento, han quedado sin resolución» (SALAS-GARCÍA, 1876, 206). 
cada cual. Como en etapas anteriores, las autoridades acortaban el período de veda a petición de los pescadores. Bastaba con que se concediese permiso a una comunidad para que otras, al sentirse agraviadas, salieran imprudentemente a la mar, contribuyendo de esta forma a la despoblación del esquilmado Mediterráneo. Es más, algunas reales órdenes, como la del 9 de octubre de 1888 y la del 27 de octubre de 1894, llegaron a abolir la veda (Asociación de Patronos Pescadores de Barcelona, 1898, 63). No importaba lo que pudiera ocurrir en el futuro, «el que venga detrás que arree» (VERA b, 1887, 204).

En este contexto, interesa destacar la actitud de los pescadores del departamento de Cartagena, partidarios de amarrar las barcas durante el verano porque es «época en que sólo capaturan las redes peces diminutos e inútiles para el consumo público, privando se acumule en las aguas del mar una riqueza que, á su oportunidad explotada, sería causa de bienestar para las poblaciones costeñas» y además «por falta de viento fresco que necesitan las parejas para verificar el arrastre con la debida velocidad» (Asociación de Patronos Pescadores de Barcelona, 1898, 59).

Consecuentes con este parecer, los pescadores valencianos preferían quedarse en tierra durante la veda, aunque se dieran permisos especiales. Los alicantinos fueron los primeros en renunciar cuando la Real Orden de 1 de junio autorizaba la actividad de la cuarta parte de la flota de cada localidad ${ }^{16}$. A ellos se sumaron pescadores de València, Vinaròs, Torrevieja, Santa Pola, Tarragona, Cambrils, Vendrell, Barcelona, Masnou, Mataró y Palma de Mallorca. Ante la postura ambivalente de la Administración, en estas comunidades la inactividad en tiempo de veda era más que nada una decisión voluntaria. En algunos puertos, como en Santa Pola, los propios pescadores se encargaban de sancionar a los infractores, «de esta forma obtienen mayores rendimientos» (SALAS-GARCÍA, 1876, 208). Sin embargo, los resultados no fueron todo lo eficaces que ellos esperaban porque, enterados de esta costumbre, los pescadores de otras provincias marítimas venían a correr sus artes por nuestro litoral. Les amparaba la ley que declaraba libre la pesca desde las tres millas de distancia de la costa ${ }^{17}$.

Por esta razón, los pescadores valencianos, y en general los del departamento, solicitaban a la Administración la adopción de medidas que juzgaban indispensables para mejorar la situación ${ }^{18}$. El acontecimiento de mayor trascendencia fue la reunión celebrada en

$16 \mathrm{Su}$ actitud les hizo merecedores del agradecimiento de las autoridades:

«Excmo. Sr.: He dado cuenta á S.M. (q. D. g.) de la carta de V.E., núm. 1.990, de 23 del actual, relativa á la renuncia hecha por los pescadores de Alicante, de utilizarse de la pesca del Bou en tiempo de veda, en los términos á que los autoriza la Real órden de $1^{\circ}$ de junio último, que señala la cuarta parte de las parejas para el disfrute de esta tolerancia, sólo permitida por el clamoreo general nacido de inveterados abusos, y en su vista se ha dignado resolver se manifieste á V.E., ordene al Comandante de Marina de la provincia de Alicante, congregue á los expresados pescadores y les manifieste el particular agrado con que S.M. ha visto ese acto de su cordura y sensatez, que demuestra desde luego, una ilustrada previsión en el resultado de las industrias que explotan, que debiera servir de norma á los demas pescadores de España, los primeros interesados en que cese para siempre todo abuso que tienda á la disminución de las especies, en cuya propagación y desarrollo va envuelto no sólo su propio porvenir y el de sus familias sino el seguro mejoramiento de un ramo tan importante para la riqueza pública.- De Real órden lo digo á V.E., á los efectos consiguientes, circulándose con esta fecha á los demas Departamentos y Apostaderos, también por disposicion de S.M.— Dios, etc.— Madrid 29 de agosto de 1877.El Ministro— Sr. Capitan general del Departamento de Cartagena». (GARCÍA SOLÁ, 1880, 156).

17 El 16 de noviembre de 1889 la Comisión Permanente de Pesca desestimaba la petición de varios propietarios y patrones de embarcaciones de València que, entre otras cosas, pedían que no se permitiese pescar en sus aguas a pescadores de provincias limítrofes (Revista de Pesca Marítima, 1889, 84-85).

18 En 1890 pescadores y armadores de parejas de bou de Peníscola y València solicitaban una veda entre junio y septiembre (Revista de Pesca Marítima, 1890, 18-19, 26-27). Unos años después, el Ayuntamiento de València, en un telegrama dirigido al Ministerio de Marina, reiteraba la conveniencia de una veda entre el primero de mayo y el 30 de septiembre (Revista de Pesca Marítima, 1898, 27). 
Tarragona el 25 de diciembre de $1896^{19}$, en la que se acordó solicitar del Ministerio de Marina el establecimiento de una veda rigurosa y absolutamente obligatoria para el arte del bou entre el primer día de mayo y el último de septiembre, mayor vigilancia y medios apropiados para hacer eficaz la labor de los guardacostas (Asociación de Patronos Pescadores de Barcelona, 1898, 81-86). Desde entonces las autoridades desestimaron todas las peticiones que se hiciron para obtener permisos o exenciones en época de veda, como las que cursaron en 1898 los pescadores de Calp, Altea, la Vila Joiosa y Vinaròs (Revista de Pesca Marítima, 1898, 26-28, 61).

\subsubsection{Expansión de las pesquerías}

Coincidiendo con la disminución de los rendimientos por sobrepesca, parte de la flota valenciana realizaba campañas de temporada en otras pesquerías. Estos desplazamientos no son nuevos, ya eran importantes en el siglo XVIII, pero sin duda recibirían un fuerte impulso con la crisis.

Los valencianos hacían campañas en el litoral andaluz. La Sociedad Económica de Amigos del País apoyaba «á las compañías que pudieran formarse para la pesca de la sardina de Ayamonte» (AGUILAR, 1876, 23). Los pescadores de la Marina aprovechaban el período de veda para faenar en caladeros africanos. En abril unos doscientos hombres a bordo de dieciséis embarcaciones salían de la Vila Joiosa en dirección al cabo Espartel, para la pesca del bonito y la caballa y no regresaban hasta septiembre. Otros doscientos, de septiembre a junio, se dirigían a «la costa de Estepona, junto á Manilva, y en el punto denominado la Savinilla» (MADOZ, 1845, II, 329).

Algunos pescadores de la Vila Joiosa trabajaron con buques viveros en Cuba. A su regreso de aguas caribeñas, se asociaron y armaron tres buques viveros para ensayar esta pesquera en Melilla, Chafarinas, el Estrecho, etc. La tuvieron que abandonar al poco tiempo por los bajos rendimientos. La producción era insuficiente para cubrir los gastos (FERNÁNDEZ, 1868, 131).

Por su parte, pescadores del Maestrat faenaban en caladeros franceses, muy frecuentados por los catalanes. El 26 de marzo de 1871 patronos de Vinaròs elevaron una queja ante el Almirantazgo por las arbitrariedades y vejaciones de que — según ellos - fueron objeto por parte de los franceses cuanto trabajaban en Sète (SALAS-GARCÍA, 1876, 501-503). Unos años después, el Convenio de 18 de diciembre de 1877 puso fin a los acuerdos pesqueros entre España y la república francesa (GUTIÉRREZ, 1885, 744 y 788). La mayor parte regresaron a casa, algunos se negaron a abandonar aquellos caladeros, faenando desde entonces de forma clandestina.

\subsection{Ligera recuperación a finales de siglo}

Sin duda, el respeto a las normas que trataban de regular la actividad pesquera contribuiría a la recuperación de los caladeros. El resultado inmediato, tal como sugiere el cuadro II, fue un aumento de la producción a finales de la centuria. En 1892, año en el que tenemos información de cada distrito pesquero, la distribución de los desembarcos (figura 4) mostraba un fuerte desequilibrio a favor del litoral meridional. A ello contribuiría el mayor número de hombres y barcos faenando en aquellas costas, donde además en 1886 ya

19 A la reunión acudieron delegaciones de los pescadores de 1'Atmella, Badalona, Barcelona, Calafell, Cambrils, Menorca, Peníscola, Sant Carles de la Ràpita, Torredembarra, Torrevieja, València, Vilanova i la Geltrú y Vinaròs. Véase a este respecto la Revista de Pesca Marítima, 1897, p. 32. 


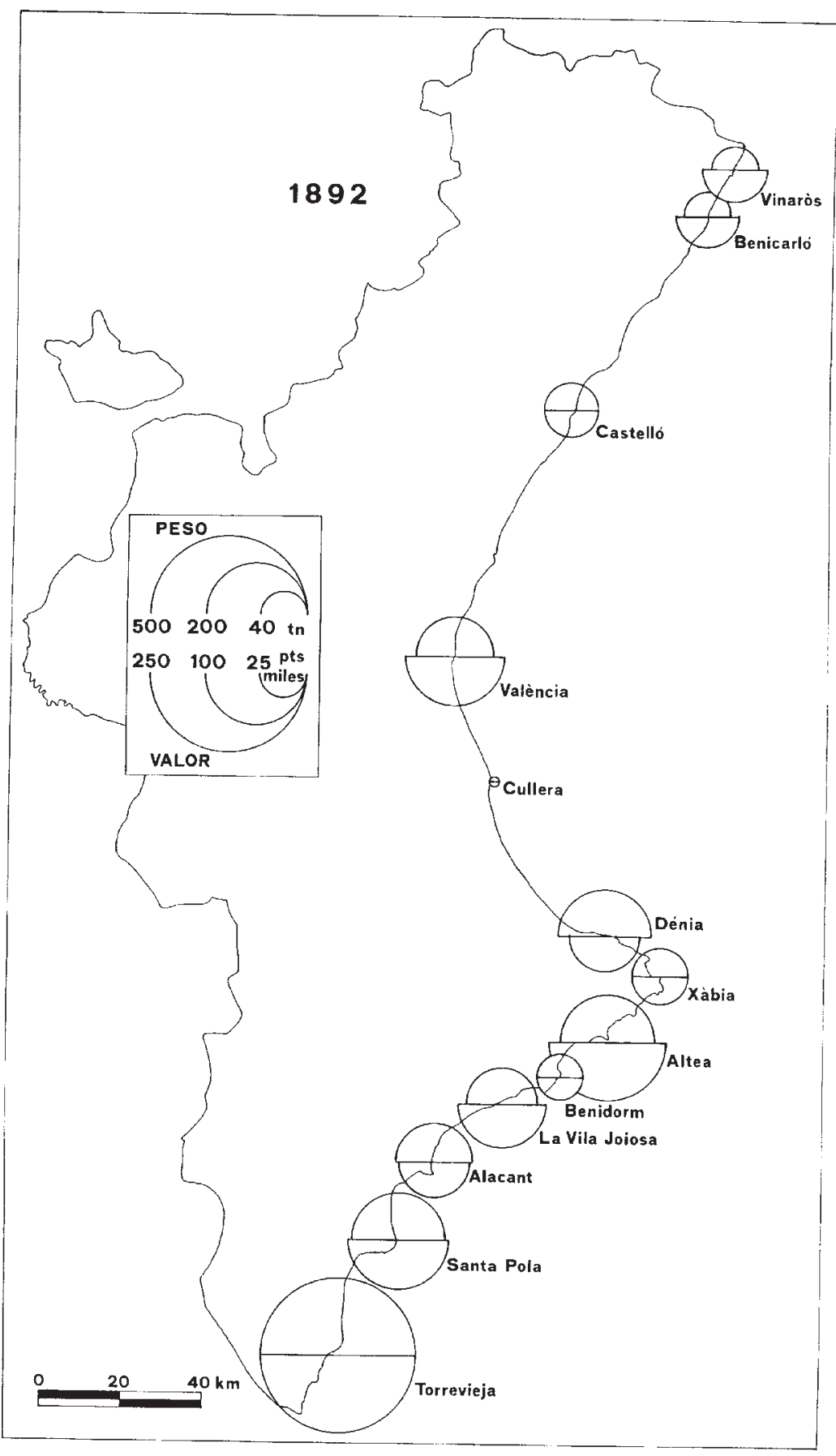

FiguRa 4. Pesca desembarcada en el litoral valenciano, en 1892. Semicírculo superior, peso; semicírculo inferior, valor. 


\section{Cuadro IV}

PESCA DESEMBARCADA EN LOS DISTRITOS VALENCIANOS, EN 1892

\begin{tabular}{|lrrrr|}
\hline Distrito & kg & Peso & & \multicolumn{2}{c|}{ Valor } \\
& & $\%$ & Pesetas & $\%$ \\
\hline Torrevieja & 498.598 & 30,2 & 244.630 & 25,4 \\
Santa Pola & 184.240 & 11,1 & 106.155 & 11,0 \\
Alacant & 121.175 & 7,3 & 52.467 & 5,5 \\
La Vila Joiosa & 106.298 & 6,4 & 73.412 & 7,6 \\
Benidorm & 37.565 & 2,3 & 25.769 & 2,7 \\
Altea & 176.340 & 10,7 & 141.872 & 14,7 \\
Xàbia & 55.150 & 3,3 & 27.575 & 2,9 \\
Dénia & 193.000 & 11,7 & 53.500 & 5,6 \\
Cullera & 2.510 & 0,2 & 2.500 & 0,3 \\
València & 129.518 & 7,8 & 109.765 & 11,4 \\
Castelló & 64.000 & 3,9 & 32.000 & 3,3 \\
Benicarló & 40.200 & 2,4 & 41.900 & 4,3 \\
Vinaròs & 44.100 & 2,7 & 51.130 & 5,3 \\
\hline TOTAL & 1.652 .694 & 100,0 & 962.675 & 100,0 \\
\hline
\end{tabular}

Fuente: Revista de Pesca Marítima, 1892. Apéndice estadístico.

Elaboración propia.

rastreaban lanchas a vapor ${ }^{20}$, las primeras que lo hicieron en el litoral valenciano. Los mayores rendimientos que se obtenían al sur del País atraían a pescadores de otras localidades $^{21}$.

Torrevieja era el distrito más importante, tanto por la cantidad como por el valor de los desembarcos. En la segunda mitad del siglo XIX, la actividad pesquera se incrementó de forma notable en aquel distrito (MORENO, 1990, 24). En 1899 la matrícula inscrita en su Ayudantía de Marina se acercaba al centenar de embarcaciones, la mayor parte construidas por carpinteros de ribera torrevejenses. Le seguían a bastante distancia los distritos de Dénia y Santa Pola. En 1860 la villa santapolera, según Gozálvez (1976, 115), contaba con 903 pescadores $^{22}$, lo que significaba que todos sus vecinos se dedicaban a la pesca (GARCÍA, 1990, 70).

En cambio, el litoral septentrional apenas reunía el 9\% de los desembarcos. Tal como señalábamos en el Grau de Castelló (VIRUELA, 1985, 40-41), aquí tenía más importancia el tráfico portuario. Vinaròs y Benicarló destacaban en la exportación de productos agríco-

20 En julio de 1886 se autorizó a don Antonio Carratalá para pescar al bou con dos lanchas a vapor en la provincia de Alacant a más de 30 millas de la costa (Revista de Pesca Marítima, 1886, pp. 32-34).

21 En junio de 1887 varias embarcaciones del Cabañal y Sant Carles de la Ràpita fueron autorizadas para inscribirse en el distrito de Torrevieja para la pesca del bou. Al año siguiente recibieron permiso embarcaciones de Vinaròs y Sant Carles para inscribirse en los distritos de Xàbia, Altea y la Vila Joiosa. Véase a este respecto: Revista de Pesca Marítima, 1887, pp. 39-49; y 1888, pp. 2, 47 y 51-52.

22 De ser exacta esta cifra, significaría que a mediados del siglo XIX Santa Pola contaba con el 77\% de los pescadores de la «provincia» de Alacant y con el 35\% del censo valenciano. Proporciones que parecen excesivas. O las estadísticas de este siglo son muy deficientes, tal como hemos indicado al principio, o el profesor Gozálvez consideró como pescadores no sólo al personal embarcado sino a todas las personas relacionadas con la actividad. 
las y vino con destino a países europeos y a Uruguay (HERNÁNDEZ, 1987, 269), sobre todo la capital del distrito, que desde 1875 contaba con un muelle nuevo (BAILA, 1990, 41).

\section{Bibliografía}

AGUILAR, E. (1876): «Memoria histórica del origen y vicisitudes de la Real Sociedad Económica de Amigos del País de Valencia», Anales de la Real Sociedad Económica de Amigos del País, Imprenta de José Rius, València, pp. 1-136.

ANÓNIMO (1888): «La escasez de pescado en nuestras costas», Revista de Pesca Marítima, t. IV, 1888, pp. 30-32.

ANÓNIMO (1892): «La vida de nuestros pescadores», Revista de Pesca Marítima, t. VIII, 1892, pp. 273-277.

ASOCIACIÓN DE PATRONOS PESCADORES DE BARCELONA (1898): «La pesca al bou», Revista de Pesca Marítima, t. XIII, 1898, pp. 56-64, 68-71, 81-86.

BAILA PALLARÉS, M. A. (1990): Desenvolupament urbà a Vinaròs, Societat Castellonenca de Cultura, Castelló, 99 p.

BALBÁS CRUZ, J. A. (1892): El libro de la provincia de Castellón, edición facsímil de la Caja de Ahorros y Monte de Piedad de Castellón, 1981, 872 p.

BERTHELOT, S. (1868): Études sur les pêches maritimes dans la méditerranée et l'océan, Challanel Ainé, Paris, 487 p.

BORJA, J. (1892): «La pesca de bou en la costa de Cataluña», Revista de Pesca Marítima, t. VIII, 1892, pp. 257-264.

BORRÁS JARQUE, J. M. (1929): Història de Vinaròs, (edición facsímil, 1979), Associació Amics de Vinaròs, Tortosa, $653 \mathrm{p}$.

BURRIEL DE ORUETA, E. L. (1971): «Desarrollo urbano de Castellón», Estudios Geográficos, n 123, Madrid, pp. 180-290.

CHABAS LLORENS, R. (1972): Historia de la ciudad de Denia, Instituto de Estudios Alicantinos, Diputación Provincial, Alicante, 260 p.

COMISIÓN DE ESTADÍSTICA GENERAL DEL REINO (1860): Anuario Estadístico de España, correspondiente a 1859 y 1860, Imprenta Nacional, Madrid, 598 p.

COMPÁN VÁZQUEZ, D. (1975-76): «La pesca marítima en España», Cuadernos Geográficos de la Universidad de Granada, no 5-6, Granada, pp. 87-175.

COMPÁN VÁZQUEZ, D. (1989): «La pesca marítima en Andalucía», en CANO, G.: Geografía de Andalucía, ed. Tartessos, t. V, pp. 201-279.

COMPÁN VÁZQUEZ, D. (1989): «La pesca» en BOSQUE, J., VIDAL, J.: Geografía de España, ed. Planeta, Barcelona, t. II, pp. 503-589.

FERNÁNDEZ, C. (1868): Anuario de la Comisión Permanente de Pesca para 1868. Resumen de sus trabajos y noticias referentes á la industria pesquera, Tipografía de Estrada Díaz y López, Madrid, $567 \mathrm{p}$.

FERNÁNDEZ, C. (1869): Anuario de la Comisión Permanente de Pesca para 1869. Resumen de sus trabajos y noticias referentes á la industria pesquera (año segundo), Tipografía de Gregorio Estrada, Madrid, $541 \mathrm{p}$.

GARCÍA MAS, A. (1990): El puerto de Santa Pola, Ayuntamiento de Santa Pola, 253 p.

GARCÍA SOLÁ, F. (1880): Memoria sobre la industria y legislación de pesca que comprende desde el año 1874 al 1879, Tipografía de Gregorio Estrada, Madrid, 830 p.

GARCÍA SOLÁ, F. (1888): «Idea general de la pesca marítima en España», Revista de Pesca Marítima, t. IV, pp. 97-110.

GOZÁLVEZ PÉREZ, V. (1976): Santa Pola: urbanismo, economía, población, Círculo de Economía de Alicante y Departamento de Geografía de Valencia, 120 p.+ fotografías.

GUTIÉRREZ VELA, R. (1885): Memoria sobre la industria y legislación de pesca que comprende desde el año 1879 al 1884, Imprenta de la viuda e hija de Fuentenebro, Madrid, 900 p.

GUTIÉRREZ VELA, R. (1894): «Estadística de Pesca, año 1892», Revista de Pesca Marítima, t. X, 1894 , pp. V-VII. 
HERNÁNDEZ SORIANO, T. (1987): «Acentuación de los contrastes durante el siglo XIX en el norte del País Valenciano», I Congrés d'Història del Maestrat, Vinaròs, pp. 265-279.

JUNTA GENERAL DE ESTADÍSTICA (1862): Anuario Estadístico de España, 1860-1861, Imprenta Nacional, Madrid, $881 \mathrm{p}$.

MADOZ, P. (1845): Diccionario Geográfico-Estadístico-Histórico de Alicante, Castellón y Valencia, edición facsímil de la Institució «Alfons el Magnànim», Diputació Provincial, València, 1982, 2 vol.

MARTÍ MESTRE, J. (1991): Les ordinacions de la costa marítima del Regne de València (1673), Insititut de Filologia Valenciana, Publicacions de 1'Abadia de Montserrat, 210 p.

MILLÁN i ROCA, Ll. (1984): «Gente del Mar del distrito de Vinaròs», Semanario Vinaròs, 7 y 14 de enero, páginas 13 y 11, respectivamente.

MILLÁN i ROCA, Ll. (1991): Naufragis a la mar de l'Ebre, Ajuntament de Sant Carles de la Ràpita, $208 \mathrm{p}$.

MINISTERIO DE MARINA: Reglamento para el gobierno y disfrute de almadrabas, 5 de abril de 1899.

MORENO VIUDES, A. (1990): Relaciones económicas y sociales de producción de la pesca artesanal en Torrevieja (Alicante, España), Memoria de Licenciatura, dirigida por el Dr. D. Manuel Oliver Narbona, Departamento de Humaniades Contemporáneas, Alicante, 2 vol.

Observaciones sobre la pesca llamada de bou; utilidad y necesidad de su uso en el golfo de Valencia, Oficina de José Ferrer de Orga, València, 1821, 32 p.

OLIVER NARBONA, M. (1982): Almadrabas en la costa alicantina, Universidad de Alicante y Caja de Ahorros Provincial de Alicante, 262 p.

OLIVER NARBONA, M. (1987): «Comunidades pesqueras alicantinas», Noray, $\mathrm{n}^{\circ}$ 1, Instituto Social de la Marina, Madrid, pp. 80-107.

PARDO, L. (1942): La Albufera de Valencia. Estudio Limnográfico, Biológico, Económico y Antropológico, Instituto Forestal de Investigaciones y Experiencias, Madrid, 268 p.

Reglamento para la pesca con el arte del bou y demás redes de arrastre remolcadas por embarcaciones, «Revista de Pesca Marítima», t. XIII, 1898, pp. 53-60.

Reseña Geográfica y Estadística de España, 1888, «Pesca», Insituto Geográfico y Catastral, Madrid, 1888, pp. 735-745.

RODRÍGUEZ SANTAMARÍA, B. (1923): Diccionario de artes de pesca de España y sus posesiones, Sucesores de Rivadeneyva, Madrid, 815 p.

ROSSELLÓ i VERGER, V. M ${ }^{\mathrm{a}}$. (1984) : 55 ciutats valencianes, Universitat de València, Secretariat de Publicacions, València, 280 p.

SALAS, J., GARCÍA SOLÁ, F. (1876): Memoria sobre la industria y legislación de pesca que comprende desde el año 1870 al 1874, Imprenta de T. Fortanet, Madrid, 741 p.+ 2 encartes estadísticos.

SALVÀ i TOMÀS, P. (1987): La pesca, ed. Síntesis, Madrid, 159 p.

VERA, F. A. (1887 a): «Extinción de la pesca al bou», Revista de Pesca Marítima, t. III, 1887, pp. 133-134.

VERA, F. A. (1887 b): «Pesca al bou», Revista de Pesca Marítima, t. III, 1887, pp. 203-204.

VICENT CORTINA, V. (1954): El puerto de Valencia, Instituto Elcano, Zaragoza, 117 p.

VIRAVENS PASTOR, R. (1876): Crónica de la muy ilustre y fiel ciudad de Alicante, edición facsímil de 1989, Banco de Alicante, Alicante, 469 p.

VIRUELA MARTÍNEZ, R. (1985): La actividad pesquera en el Grau de Castelló, Departamento de Geografía, València, 103 p.

VIRUELA MARTÍNEZ, R. (1993): «Difusió de la pesca del bou en el litoral valencià (segles XVIII i XIX», Cuadernos de Geografía, nº 53, València, pp. 145-161. 